\title{
PENGARUH RELATIONSHIP MARKETING TERHADAP CUSTOMER LOYALTY DI PT. MPM FINANCE CABANG PANAM PEKANBARU
}

\author{
Oleh: \\ *)Putra Budi Ansori \\ **) Dosen Sekolah Tinggi Ilmu Ekonomi Riau
}

\begin{abstract}
This research was conducted in the research conducted at PT MPM Finance, branches of Panam Pekanbaru, HR Soebrantas KM 12 No:A7 Pekanbaru City in 2017. Research aims to understand the influence of relationship marketing to customer loyalty in PT.MPM finance the branches of panam pekanbaru. The population in this study is 8,943 consumers who at PT MPM Finance, branches of Panam Pekanbaru, Then the number of samples is rounded to 99 consumers, after calculated by the Slovin formula. The sampling technique was done by accidental sampling. It means respondents (a subject) selected by chance alone from members of the population who are willing to are only sampled.From the analysis of single linear regression equation was formulated:

$Y=7,988+0,639 X$. Where, constant at 7,988, meaning that if the variable Relationship Marketing is 0, then the dependent variable Relationship Marketing of 7,988 and a regression coefficient of variable variable Relationship Marketing amounted to 0,639, which means that if the Customer Loyalty increased by 1 point, then the Customer Loyalty also will be increased by 0,639. The coefficient is positive, meaning a positive relationship between the Relationship Marketing of the Customer Loyalty. The higher the Relationship Marketing the increasing Customer Loyalty. Based on test result of significant test (t), obtained t count value for independent variable of Relationship Marketing $(X)$ is 12,486. The t table value with $d f=$ 99-2 and the 5\% or 0.05 confidence level, is 1.98472. From these values can be concluded $t$ count $>t$ tabel means, there is a significant relationship or influence between Relationship Marketing to the Customer Loyalty of PT MPM Finance, branches of Panam Pekanbaru. Obtained value of $R 2$ or $R$ Square equal to 0,616 or 61,6\%. This value can be interpreted that changes in the value of Customer Loyalty are influenced by changes in the value of free Relationship Marketing by 61,6\% while 38,4\% is determined by other variables that do not exist in this research model.
\end{abstract}

\section{Keyword : Relationship Marketing, Customer Loyalty}

\section{Pendahuluan}

Ketatnya persaingan antar usaha saat ini mendorong setiap perusahaan menawarkan keunggulan produk, peningkatan pelayanan dan termasuk kemudahan-kemudahan agar konsumen tertarik pada produk/jasa yang ditawarkan. Setelah beberapa waktu, konsumen mempunyai persepsi sendiri terhadap keunggulan yang ditawarkan selanjuntya menjadi pelanggan bagi perusahaan tersebut. Dalam situasi ini (setelah ada Pelanggan), pekerjaan yang terberat bagi perusahaan adalah mempertahankan pelanggan yang sudah ada dan mencapai kemajuan yang berikutnya sesuai dengan perkembangan zaman.Karena paradigma pemasaran 
saat ini telah bergeser, tidak hanya menciptakan transaksi untuk mencapai keberhasilan pemasaran tetapi perusahaan juga menjalin hubungan dengan pelanggan dalam waktu yang panjang. Paradigma tersebut disebut relationship marketing.

Maka, makna terdalam dari relationship marketing adalah hubungan yang saling percaya dan saling menguntungkan dalam kurun waktu yang lama dalam transaksi terus menerus. Hingga penelitian ini lebih fokus pada praktek dari proses relationship marketing di perusahaan lembaga keuangan, karena perusahaan lembaga keuangan merupakan salah satu penyedia jasa yang menerapkan keunggulan pelayanan, ramah-tamah dan saling memahami antara perusahaan dan konsumen.

Dari hasil pengamatan awal bahwa konsumen yang mengajukan kredit di PT. MPM Finance Cabang Panam Pekanbaru mengalami fluktuasi. Pada tahun 2013 jumlah Konsumennya sebanyak 8.038 orang, tahun 2014 mengalami peningkatan menjadi 9,411 orang, tahun 2015 jumlah konsumen mengalami kenaikan lagi sebesar 10.488 orang. Selanjutnya tahun 2016 jumlah konsumen kembali mengalami penurunan menjadi 9.926 orang. Pada tahun 2017 jumlah konsumen mengalami penurunan kembali sebesar menjadi 8.943 orang.

Turun-naiknya jumlah konsumen PT. MPM Finance Cabang Panam Pekanbaru yang di sebabkan oleh mulainya bermunculan kompetitor yang sama dengan PT. MPM Finance Cabang Panam Pekanbaru. Banyak pilihan tersebut membuat konsumen memiliki peluang yang luas untuk mendapatkan produk atau jasa yang sama sesuai dengan keinginanan dan kebutuhannya.

Salah satu alternatif pendekatan pemasaran yang saat ini mulai banyak digunakan oleh perusahaan jasa adalah relationship marketing atau pemasaran rasional. Relationship marketing adalah hubungan dan ikatan jangka panjang antara produsen, konsumen dan pemasok serta pelaku lainnya. Dengan kata lain, relationship marketing merupakan rancangan integratif yang memperkokoh kempetensi pemasaran perusahaan.

Relationship marketing dijadikan penghubung untuk mengetahui kepuasan pelanggan terhadap produk yang telah dibelinya dan juga dapat mengetahui variabel apa yang menyebabkan pelanggan puas atau tidak puas dan mengetahui kebutuhan, keinginan dan harapan pelanggan sehingga perusahaan dapat membuat langkah-langkah strategis untuk mendapatkan kepuasan pelanggan dan dapat mempertahankan pelanggan. 
PT. MPM Finance Cabang Panam Pekanbaru menerapkan relationship marketing dengan mengunjungi konsumen ketempat usahanya secara berkala dan memberikan pelatihan kewirausahaan. Kegiatan tersebut membuat konsumen merasa di perhatikan dan dibina dengan baik, dan diharapkan hal tersebut meningkatkan hubungan yang baik antara konsumen dengan perusahaan, dan perusahaan juga dapat mengetahui tingkat kepuasan konsumen terhadap jasa yang diberikan.

Karena menurunnya jumlah konsumen juga berakibat pada naik- turunnya realisasi kredit yang disalurkan oleh PT. MPM Finance Cabang Panam Pekanbaru dari tahun ke tahun.

Berdasarkan masalah di atas, peneliti merumuskan masalah dalam penelitian ini adalah sebagai berikut: "Apakah Relationship Marketing berpengaruh Terhadap Customer Loyalty di PT. MPM Finance Cabang Panam Pekanbaru.?”.

\section{Tinjauan Pustaka}

\section{Pengertian Relationship Marketing ( Hubungan Pemasaran )}

Menurut Buchari Alma (2011:271) menyatakan bahwa Relationship Marketing adalah upaya mengenal konsumen lebih baik sehingga perusahaan dapat memenuhi needs dan wants mereka. Sedangkan menurut Zeithaml dalam Buchari Alma (2011:271) mengungkapkan istilah Relationship Marketing adalah suatu filosofi menjalankan bisnis yang fokus/ terutama pada pelayanan pada pelanggan yang sudah ada, dibandingkan dengan mencari langgan baru.

Menurut Kotler dan Keller (2009:21), Relationship marketing merupakan suatu praktek membangun hubungan jangka panjang yang memuaskan dengan pihak-pihak kunci yang meliputi pelanggan, pemasok, dan penyalur guna mempertahankan preferensi dan bisnis dalam jangka panjang. Sementara itu menurut Kotler dan Amstrong (2008:575) menyebutkan Relationship marketing adalah proses menciptakan, memelihara dan mengalihkan keunggulan, muatan nilai hubungan antara pelanggan dan pemegang saham lainnya.

Berdasarkan pengertian di atas maka dapat disimpulkan bahwa Relationship Marketing adalah suatu program yang dilakukan oleh perusahaan untuk menjaga dan mempertahankan hubungan yang lebih baik serta memberikan kepuasan yang maksimal kepada pelanggan agar kedua pihak mendaptkan keuntungan dan manfaat jangka panjang. Sehingga mereka menjadi konsumen yang loyal.

Relationship marketing terbagi menjadi dua bagian :

1. Understanding customer expectation (Memahami harapan Pelanggan) 
Understanding customer expectation adalah kegiatan yang melibatkan kemampuan perusahaan untuk melakukan identifikasi apa yang diinginkan oleh konsumen dan memasarkan barang dan jasa diatas tingkat yang mereka harapkan. Tidak mudah untuk mengidentifikasi apa yang diharapkan oleh seorang pelanggan, pelanggan ingin pemasar mengetahui keinginankeinginan mereka. Pelanggan juga ingin pemasar memahami prefensi, gaya hidup dan hobinya. Untuk memenuhi keinginan pelanggan yang semakin kompleks itu, sebuah perusahaan harus bisa mengumpulkan informasi sebanyak-banyaknya tentang pelanggan dan menggunakannya pada saat yang tepat. Dengan demikian, seorang pelanggan merasa membeli sesuatu produk atau jasa yang sesuai dengan apa yang mereka harapkan.

2. Building service pertnership (Membangun pelayanan kemitraan)

Pengalaman kemitraan ada ketika suatu perusahaan bekerja sama secara erat dengan konsumen dan menambahkan pelayanan yang di inginkan oleh konsumen atas suatu produk perusahaan.

Beberapa pertimbangan dalam membangun pelayanan kemitraan menurut Wibowo S, (2006) adalah:

1. Kedua pihak yaitu pembeli dan penjual memiliki fokus yang sama mengenai kebutuhan spesifik yang ingin dicapai masing-masing harus merasa dalam posisi “win-win”.

2. Kedua pihak merupakan kolaboratif yang harus bekerjasama mencapai tujuan yang sama.

3. Kedua pihak harus melakukan antisipasi adanya masalah.

Langkah-langkah dalam relationship marketing menurut Kotler dan Keller (2009:25):

a. Mengidentifikasi pelanggan utama, memilih lima sampai sepuluh pelaggan utama sebagai target relationship marketing, penambahan pelanggan dapat disisipkan sehingga memperlihatkan kinerja pertumbuhan yang luar biasa,atau merupakan pelopor pengembangan industri baru.

b. Mengukur nilai relasi dan program relationship marketing.

c. Memanajemen dan memotivasi organisasi bagi relationship marketing, membangkitkan dan mengkomunikasikan organisasi dalam mendukung relationship marketing menjadikan organisasi lebih sebagai kumpulan pikiran, dibandingkan dengan fungsi organisasi.

d. Marketing sebagai himpunan pikiran terhadap fungsi, perpaduan dan kerjasama antar dalam organisasi dalam mendukung relationship marketing menjadikan organisasi lebih sebagai kumpulan pikiran, dibandingkan dengan fungsi organisasi.

e. Meningkatkan dan memantapkan keterkaitan dengan pelanggan, meliputi perencanaan dan penetapan tujuan, strategi, tindakan spesifik, dan sumber daya yang dibutuhkan. 
Selanjutnya menurut Abdullah dan Tantri (2012: 42), kita perlu membedakan lima tingkat Relationship Marketing yaitu:

a. Dasar

Wiraniaga menjual produk umum tidak menghubungi pelanggan lagi (misalnya wiraniaga mobil hanya menjual mobil).

b. Reaktif

Wiraniaga menjual produk dan meminta pelanggan menghubungi bila pelanggan punya pertanyaan atau keluhan.

c. Bertanggung Jawab

Wiraniaga menghubungi pelanggan segera setelah penjualan untuk menanyakan apakah produk memenuhi harapan pelanggan. Wiraniaga juga mengumpulkan saran-saran perbaikan produk dan setiap keluhan yang ada. Informasi ini membantu perusahaan untuk terus menyempurnakan produk.

d. Proaktif

Wiraniaga menghubungi pelanggan dari waktu ke waktu dengan saran mengenai penggunaan produk yang disempurnakan atau produk baru yang berguna.

e. Kemitraan

Perusahaan terus bekerja sama dengan pelanggan untuk mencapai penghematan bagi pelanggan atau membantu pelanggan bekerja lebih baik.

Sedangkan menurut Kotler dan Amstrong (2008: 583), Dimensi Relationship Marketing terdiri dari:

a. $\quad$ Trust (Kepercayaan)

Kepercayaan (Trust) adalah hal dasar bagi mitra dalam melakukan pertukaran. Perusahaan mendapati bahwa melakukan transaksi dengan dasar saling percaya akan memberikan hasil yang melebihi dibandingkan dengan perusahaan semata-mata bertindak untuk kepentingan sendiri. Kepercayaan terdiri dari 4 elemen yaitu reliability, openness, competence, dan concern.

b. Commitmen (Komitmen)

Komitmen hubungan (Commitmen of the Relationship) adalah inti dari semua hubungan kerja yang sukses dan unsur paling penting dalam keberhasilan hubungan jangka panjang, termasuk didalamnya hubungan antara penjual dan pembeli. Komitmen merupakan keinginan perusahaan untuk menjaga hubungan baik dengan pelanggan selamanya. Hal ini menunjukkan 
tingkat komitmen yang lebih tinggi dari kewajiban untuk membuat hubungan berjalan dengan baik dan membuatnya saling memuaskan dan menguntungkan.

c. Communication (Komunikasi)

Komunikasi (Communication) adalah pertukaran formal maupun informal dan berbagi informasi yang berarti tepat waktu antara pembeli dan penjual. Komunikasi khusunya yang tepat waktu dapat memupuk kepercayaan dan membantu dalam menyelesaikan perselisihan serta menyelaraskan pentingnya pertukaran dalam hubungan bisnis. Komunikasi juga bisa membangun kepercayaan. Selain itu komunikasi juga dapat digunakan untuk meningkatkan kemampuan hubungan untuk menyelaraskan harapan dan persepsi.

Menurut Tandjung (2004:121) empat dimensi relationship marketing adalah:

\section{Bonding}

Ketergantungan antara kedua belah pihak harus cukup kuat, sehingga hubungan keduanya dapat bertahan lama. Seorang pelanggan bila merasa tidak memiliki ketergantungan yang kuat terhadap penjual, maka kemungkinan pelanggan tersebut akan sering berganti pemasok.

\section{Empathy}

Seorang penjual harus memiliki kepedulian (empathy) kepada pelanggan, artinya seorang penjualan hendaknya peduli terhadap permasalahan yang dihadapai pelanggan dan memperhatikan sudut pandang pelanggan dalam mengatasi suatu masalah.

\section{Reciprocity}

Hubungan jangka panjang haruslah saling memberi dan menerima. Artinya, baik penjual maupun pelanggan sama-sama mendapat keuntungan. Pelanggan yang menginginkan diskon besar, tentunya harus mengimbangi dengan pembayaran tunai.

\section{Trust}

Trust lebih dari sekedar believe, meskipun kedua kata tersebut memiliki arti yang hampir sama. Masing-masing pihak bila memiliki komitmen yang kuat, maka akan menciptakan rasa sangat percaya (trust) dan memperkuat hubungan.

\section{Customer Loyalty (Kesetiaan Pelanggan)}

Pelanggan yang dianggap loyal akan berlangganan atau melakukan pembelian ulang selama jangka waktu tertentu. Pelanggan yang loyal sangat berarti bagi badan usaha karena biaya untuk mendapatkan pelanggan baru mahal dari pada memelihara pelanggan lama (Peter dan Olson, 2002:45). 
Menurut Amin Widjaja (2008:6) bahwa " Customer Loyalty " adalah kelekatan pada suatu merek, toko, pabrikan, pembelian jasa, atau entitas lain berdasarkan sikap yang menguntungkan dan tanggapan yang baik seperti membeli ulang.

Menurut Griffin (2005:11) mengemukakan bahwa loyalitas yang meningkatkan dapat menghemat biaya perusahaan setidaknya di 6 (enam) bidang :

1. Biaya pemasaran menjadi berkurang (biaya pengambilalihan pelanggan lebih tinggi dari pada biaya memepertahankan pelanggan).

2. Biaya transaksi menjadi lebih rendah, seperti negosiasi kontak dan pemprosesan order.

3. Biaya perputaran pelanggan (customer turnover) menjadi berkurang ( lebih sedikit pelanggan hilang yang harus digantikan).

4. Keberhasilan Cross-selling (Penjualan Silang) menjadi meningkat, menyebabkan pangsa pelanggan yang lebih besar.

5. Pemberitaan dari mulut kemulut menjadi lebih positif, dengan asumsi para pelanggan yang loyal juga merasa puas.

6. Biaya kegagalan menjadi menurun (Pengurangan pengerjaan ulang, klaim garansi dan sebagainya).

Karyawan-karyawan pada bisnis jasa sering dipengaruhi oleh interaksi harian mereka dengan konsumen-konsumen perusahaan, karena cenderung lebih suka bekerja dengan organisasi-organisasi yang konsumennya loyal dan puas.

\section{Faktor-faktor yang mempengaruhi loyalitas}

Stanton diterjemahkan mangkunegara (2002, hal. 39) yang menegemukakan bahwa ada tiga faktor yang mempengaruhi loyalitas konsumen sebagai berikut:

1. Kekuatan Sosial Budaya yang terdiri dari :

a. Faktor Budaya

Budaya dapat didefinisikan sebagai hasil kreativitas manusia dari satu generasi kegenerasi berikutnya yang sangat menentukan bentuk perilaku dalam kehidupannya sebagai anggota masyarakat.

b. Faktor Kelas Sosial

Kelas sosial didefinisikan sebagai suatu kelompok yang terdiri dari sejumlah orang yang mempunyai kedudukan yang seimbang dalam masyarakat.

c. Faktor Kelompok Panutan 
Kelompok anutan didefinisikan sebagai suatu kelompok orang yang mempengaruhi sikap, pndapat, norma, dan perilaku konsumen. Kelompok anutan ini merupakan kumpulan keluarga, kelompok atau organisasi tertentu.

d. Faktor Keluarga

Keluarga dapat didefinisikan sebagai suatu unit masyarakat yang terkecil yang perilaku sanagat mempengaruhi dan menentukan dalam pengambilan keputusan membeli.

2. Faktor karakteristik pribadi (perilaku Konsumen)

Keputusan konsumen juga dipengaruhi oleh karakteristik pribadi. Karakteristik tersebut meliputi:

a. Usia dan tahap siklus hidup

Orang membeli barang dan jasa yang berbeda sepanjang hidupnya. Mereka makan makanan bayi selama tahun-tahun awal hidupnya, banyak ragam makanan selama tahun-tahun pertumbuhan dan kedewasaan serta selama tahun-tahun berikutnya. Selera orang terhadap pakaian, perabot, dan rekreasi juga berhubungan dengan usia.

b. Pekerjaan dan lingkungan ekonomi.

Pekerjaan seseorang juga mempengaruhi pola konsumsinya. Pekerja kerah biru akan membeli pakaian kerja, sepatu kerja, dan kotak makan siang.

c. Gaya hidup

Orang-orang yang berasal dari sub-budaya, kelas sosial dan pekerjaan yang sama dapt memiliki gaya hidup yang berbeda.

d. Kepribadian dan konsep diri

Masing-masing orang memiliki kepribadian yang berbeda yang mempengaruhi perilaku pembeliannya.

3. Kekuatan faktor psikologis pribadi.

a. Faktor Pengalaman Belajar.

Belajar dapat didefinisikan sebagai suatu perubahan perilaku akibat pengalaman sebelumnya. Perilaku konsumen dapat dipelajari karena sangat dipengaruhi oleh pengalaman belajarnya. Pengalaman belajar konsumen akan menentukan tindakan pengambilan keputusan membeli.

b. Faktor Sikap dan Keyakinan. 
Sikap dapat didefinisikan sebagai suatu penilaian kognitif seseorang terhadap suka atau tidak suka, perasaan emosional yang tindakannya cenderung kearah bebagai objek atau ide. Sikap dapat pula diartikan sebagai kesiapan seseorang untuk melakukan suatu tindaan atau aktivitas.

c. Konsep Diri

Konsep diri dapat didefinisikan sebagai cara kita melihat diri sendiri dan dalam waktu tertentu sebagai gambaran tentang apa yang kita pikirkan.

\section{Indikator-indikator Customer Loyalty}

Menurut Kotler dan Keller, 2006:57 ada beberapa Indikator yang mempengaruhi loyalitas pelanggan :

a. Repeat Purchase yaitu kesetiaan terhadap pembelian produk.

b. Retention yaitu ketahanan terhadap pengaruh yang negatif mengenai perusahaan.

c. Referrals yaitu mereferensikan secara total esistensi perusahaan.

\section{Pengaruh Relationship Marketing terhadap Customer Loyalty.}

Relationship marketing merupakan cara bagaimana suatu perusahaan menjalin hubungan baik dengan pelanggannya agar pelanggan melakukan pembelian kembali secara berkelanjutan. Sedangkan Customer Loyalty merupakan kesetiaan konsumen terhadap produk sehingga melakukan pembelian secara berulang-ulang. Semakin baik Relationship marketing yang dilakukan oleh suatu perusahaan maka semakin besar loyalitas yang diberikan konsumen.

Menurut Tjiptono (2008:70), pada tataran strategi, upaya mewujudkan kepuasan pelanggan membutuhkan komitmen, baik menyangkut dana maupun sumber daya manusia. Relationship marketing merupakan salah satu strategi dalam rangka memuaskan pelanggannya. Relationship marketing memengaruhi kepuasan pelanggan karena relationship merupakan upaya menjalin relasi positif jangka panjang yang saling menguntungkan.

\section{Metode Penelitian}

Penelitian ini dilakukan pada PT. MPM Finance Cabang Panam Pekanbaru yang beralamat di Jalan.HR. Soebrantas KM 12 Ruko No.A7 Kecamatan Tampan Kota Pekanbaru Riau. Teknik analisa data menggunakan analisis deskriptif dan kuantitatif. Dengan metode regresi linear sederhana, yaitu suatu metode statistik yang digunakan untuk mengetahui pengaruh antara satu variabel bebas terhadap variabel terikat. 
Dengan metode pengambilan sampel accidental sampling. Artinya responden (subjek) yang dipilih secara kebetulan saja dari anggota populasi yang bersedia dijadikan sampel, sebanyak 99 orang responden

Metode pengumpulan data yang digunakan dalam penelitian ini meliputi metode kuesioner, wawancara dan observasi (Umar, 2005:46).

a. Kuesioner yaitu teknik penumpulan data yang dilakukan dengan cara memberi seperangkat pertanyaan atau pernyataan tertulis kepada responden untuk dijawabnya tentang sejauh mana pengaruh Relationship Marketing terhadap Customer Loyalty pada PT. MPM Finance Cabang Panam Pekanbaru.

b. Wawancara yaitu dengan mengadakan tanya jawab kepada pihak perusahaan untuk dapat memperoleh informasi mengenai hal, kondisi, serta situasi yang bersangkutan dengan masalah yang sedang dilakukan penelitian ini.

Sesuai dengan jenis dan sifat penelitian ini, maka seluruh data yang akan dikumpulkan disusun sistematis dan deskriptif. Metode analisis data yang digunakan dalam penelitian ini adalah skala likert digunakan untuk mengukur sikap, pendapat, dan presepsi sosial, Skor jawaban respondent dalam penelitian. Untuk membantu dalam pengolahan data tersebut digunakan program SPSS (Statistical Package For Social Science). Sedangkan alat uji yang digunakan untuk menguji persamaan regresi serta koefisien determinasi dan standar errornya dan untuk melihat pengaruh dari variabel bebas (independen) terhadap variabel terikat (dependen) di dalam penulisan ini.

\section{Hasil Penelitian \\ Pengujian Data}

Dalam melakukan penelitian ini penulis menggunakan instrumen berupa kuesioner yang terdiri dari variabel Relationship Marketing sebanyak 12 item dan Customer Loyalty sebanyak 10 item pernyataan.

\section{Uji Vadilitas}

Uji validitas bertujuan untuk mengetahui item-item atau pertanyaan yang valid dalam menentukan sebuah variabel. Pengujian dilakukan dengan membandingkan nilai korelasi (r) hitung dengan $r$ tabel. Dimana kriteria pengujiannya jika nilai $r$ hitung $>r$ tabel maka dikatakan item pertanyaan tersebut valid dan jika nilai $r$ hitung $<\mathrm{r}$ tabel maka dikatakan item pertanyaan tersebut tidak valid dan dinyatakan pertanyaan tersebut gugur. 
Uji validitas akan menguji masing-masing variabel yang digunakan dalam penelitian ini, dimana keseluruhan variabel diperoleh nilai $r$ hitung seluruh pernyataan $>r$ tabel $(0,1975)$.

Berdasarkan hasil perhitungan uji validitas variabel Relationship Marketing sebanyak 12 item dinyatakan valid dan Customer Loyalty sebanyak 10 item alat ukur tersebut semua dinyatakan valid.

Artinya adalah alat ukur yang digunakan validdan bisa digunakan sebagai alat pengumpul data.

\section{Uji Realibilitas}

Koefisien cronbach alpha yang lebih dari 0,60 menunjukkan keandalan (reliabilitas) instrumen. Selain itu, yang semakin mendekati 1 menunjukkan semakin tinggi konsistensi internal reliabilitasnya.

Tabel 1

Hasil Uji reliabilitas

\begin{tabular}{|l|c|c|c|}
\hline \multicolumn{1}{|c|}{ Variabel } & Cronbach's Alpha & Batas Reliabilitas & Keterangan \\
\hline Relationship Marketing & 0,766 & 0.60 & Reliabel \\
\hline Customer Loyalty & 0,641 & 0.60 & Reliabel \\
\hline
\end{tabular}

Sumber : Data Olahan, 2017.

Hasil pengujian reliabilitas pada Tabel diatas menunjukkan bahwa nilai koefisien Alpha dari variabel-variabel yang diteliti menunjukkan hasil yang beragam dan variabel menghasilkan nilai Cronbach Alpha lebih besar dari 0,60. Dengan demikian dapat disimpulkan bahwa alat ukur yang digunakan dalam penelitian ini adalah reliabel.

\section{Koefisien Determinasi $\left(\mathbf{R}^{2}\right)$}

Besarnya kontribusi variabel independen yaitu Relationship Marketing (variabel X) terhadap variabel dependen yaitu Customer Loyalty (variabel Y) dapat dihitung dengan mencari nilai koefisien determinasi. Dari hasil output SPSS didapatkan :

\section{Tabel 2 Analisis Determinasi}

\begin{tabular}{|c|l|r|r|r|}
\multicolumn{5}{|c}{ Model Summary } \\
\hline Model & $\mathrm{R}$ & R Square & \multicolumn{1}{c|}{$\begin{array}{c}\text { Adjusted R } \\
\text { Square }\end{array}$} & $\begin{array}{c}\text { Std. Error of } \\
\text { the Estimate }\end{array}$ \\
\hline 1 & $.785^{\mathrm{a}}$ & .616 & .612 & 2.55983 \\
\hline
\end{tabular}

a. Predictors: (Constant), RELATIONSHIP MARKETING

b. Dependent Variable: CUSTOMER LOYATY

Sumber ; Data olahan ; 2017

Dari hasil tersebut didapatkan nilai koefisien determinasi (R Square) sebesar 0,616 atau 61,6\%. Jadi dapat disimpulkan bahwa variabel Relationship Marketing memberikan kontribusi terhadap perubahan-perubahan variabel Customer Loyalty sebesar 61,6\%. sementara sisanya sebesar 38,4\% (100\%-61,6\%) dipengaruhi oleh faktor-faktor lainnya yang tidak diteliti dalam penelitian ini. 


\section{Uji t}

Berdasarkan hasil perhitungan dengan menggunakan bantuan SPSS, diperoleh data-data sebagai berikut:

Berdasarkan pada tabel 3 di atas diperoleh nilai t hitung sebesar 12,486. Sedangkan nilai kritis menurut tabel dengan tingkat signifikansi 5\% dengan menggunakan rumus t tabel ( $\alpha$ / 2; $\mathrm{n}-\mathrm{k}$ ) k= 2 dan $\mathrm{n}=99$ adalah 1,98472, Karena thitung > t tabel maka Ho ditolak. Artinya terdapat pengaruh Relationship Marketing terhadap Customer Loyalty. Dengan arti kata Hipotesis (Ha) diterima. Nilai t positif menunjukkan bahwa variable Relationship Marketing mempunyai hubungan yang searah dengan Customer Loyalty pada PT. MPM Finance Cabang Panam Pekanbaru.

\section{Pembahasan}

Hasil penelitian diperoleh bahwa ada pengaruh Relationship Marketing terhadap Customer Loyalty pada PT. MPM Finance Cabang Panam Pekanbaru, penelitian ini sejalan dengan penelitian yang dilakukan oleh Firdaus (2015) STIE Riau. Bahwasanya ada pengaruh Relationship Marketing Terhadap Customer Loyalty.

Selain itu penelitian ini menguatkan penelitian sebelumnya yang dilakukan oleh Yuliana Rahmawati (2014) meneliti tentang pengaruh Relationship Marketing Terhadap loyalitas Konsumen pada PT. Bank Negara Indonesia (Persero) Tbk. Cabang malang.

\section{Kesimpulan dan Saran}

\section{Simpulan}

Simpulan penelitian ini antara lain :

1. Untuk melihat pengaruh variabel independen yaitu Relationship Marketing (variabel X) terhadap variabel dependen yaitu Customer Loyalty (variabel Y), menggunakan analisis regresi sederhana dengan hasil adalah $\mathbf{Y}=\mathbf{7 , 9 8 8}+\mathbf{0 , 6 3 9 X}$. Artinya bahwa nilai dari a adalah 7,988 nilai ini menunjukkan bahwa $1 \quad 8 \quad$ variabel Relationship Marketing (variabel X) bernilai nol, maka Customer Loyalty(varıabel Y) sebesar 7,988 Sedangkan nilai dari b adalah 0,639, artinya bahwa ketika terjadi peningkatan nilai variabel Relationship Marketing (variabel X) sebesar 1 (satu) satuan, maka Customer Loyalty(variabel Y) akan meningkat sebesar 0,639 satuan

2. Nilai t hitung sebesar 12,486 . Sedangkan nilai kritis menurut tabel dengan tingkat signifikansi $5 \%$ dengan menggunakan rumus t tabel $(\alpha / 2 ; \mathrm{n}-\mathrm{k}) \mathrm{k}=2$ dan $\mathrm{n}=83$ adalah 1,98472, Karena 
thitung > t tabel maka Ho ditolak. Artinya terdapat pengaruh Relationship Marketing terhadap Customer Loyalty. Dengan arti kata Hipotesis (Ha) diterima. Nilai t positif menunjukkan bahwa variable Relationship Marketing mempunyai hubungan yang searah dengan Customer Loyalty pada PT. MPM Finance Cabang Panam Pekanbaru

3. Nilai koefisien determinasi (R Square) sebesar 0,462 atau 61,6\%. Jadi dapat disimpulkan bahwa variabel Relationship Marketing memberikan kontribusi terhadap perubahan-perubahan variabel Customer Loyalty sebesar 61,6\%. sementara sisanya sebesar 55,0\% (100\%-61,6\%) dipengaruhi oleh faktor-faktor lainnya yang tidak diteliti dalam penelitian ini

\section{Saran}

Dari kesimpulan penelitian diatas, maka penulis dapat memberikan masukan sebagai berikut:

1) Berdasarkan pengolahan data, Relationship Marketing pada PT. MPM Finance Cabang Panam Pekanbaru termasuk pada kategori baik namun tetap harus ditingkatkan agar Customer Loyalty dapat tercipta. Untuk peningkatan relationship marketing sebaiknya Karyawan PT. MPM Finance Cabang Panam Pekanbaru menjelaskan tentang Produk yang dipasarkannya.

2) Berdasarkan dari pengolahan data, Customer Loyalty PT. MPM Finance Cabang Panam Pekanbaru Pekanbaru berada pada kategori baik. Untuk peningkatan Customer Loyalty sebaiknya PT. MPM Finance Cabang Panam Pekanbaru dapat meredam berita negatif mengenai produk PT. MPM Finance Cabang Panam Pekanbaru dan menginformasikan berita positif kepada konsumen

3) Untuk peneliti selanjutnya yang meneliti hal yang sama perlu disarankan agar dimasukan variabel-variabel lain yang dapat mempengaruhi Customer Loyalty sehingga dapat membandingkan seberapa besar tingkat pengaruh dari variabel-variabel tersebut dan dapat diketahui variabel mana yang dominan atau terbesar yang mempengaruhi Customer Loyalty

\section{Daftar Pustaka}

Alma. Buchari. 2011. Manajemen pemasaran dan pemasaran jasa. Alfabeta. Bandung.

Firdaus (2015), Skripsi STIE Riau dengan judul Pengaruh Relationship Marketing Terhadap Customer Loyalty (Studi pada USP Swamitra Fatma Pesona Adi Karya Pekanbaru)

Candra, Putriella. 2016. "Pengaruh Relationship Marketing Terhadap Loyalitas Konsumen Pada PT. Bank Syariah Mandiri Kcp. Panam. Pekanbaru 
Nova Yuliana Rahmawati. 2014. Dengan judul Pengaruh Relationship Marketing Terhadap Loyalitas konsumen pada PT. bank Negara Indonesia Tbk. Cabang malang.

Kotler. Philip and Keller, Kevin Lane. 2009. Manajemen Pemasaran. Edisi Ketiga Belas. Jilid 1. Erlangga. Jakarta

Kotler and Amstrong, Gary. 2008. Prininsip-Prinsip Pemasaran. Edisi 12. Jilid 1. Erlangga. Jakarta.

Wibowo, S, 2006, “Implementasi Relationship Marketing Pada Industri “, Utilitas

Griffin, Jill. 2005. Customer Loyalty. Erlangga. Jakarta.

Supranto. J. 2009. Statistik Teori dan Aplikasi. Edisi 7. Jilid 2. Penerbit Erlangga. Jakarta.

Abdullah. Thamrin Dan Tantri Francis.2012. Manajemen Pemasaran. PT. Raja Grafindo Persada. Jakarta.

Ghozali. Imam. 2005. Analisis Multivariate Dengan Program SPSS. Badan Penerbit Universitas Diponegoro. Semarang.

Suharsimi, Arikunto. 2010. Prosedur Penelitian. Jakarta: Rineka Cipta.

Swastha. Basu. Dan Irawan. 2008. Manajemen Pemasaran Modern. Liberty. Yogyakarta.

Tjiptono, Fandy, 2008. Manajemen Jasa. Edisi keempat. Andi. Yogyakarta.

Kotler, Philip, 2004 Metode Riset untuk Bisnis \& Ekonomi : Bagaimana Meneliti \& Menulis Tesis. Erlangga, Jakarta

Widjaja, Amin Tunggal. 2008. Customer RelationshipManagement:Manajemen Hubungan Pelanggan, Konsep dan Kasus. Jakarta: Harvarindo 